\title{
Effects of Phosphate Binder Therapy on Vascular Stiffness in Early-Stage Chronic Kidney Disease
}

\author{
Michael E. Seifert ${ }^{a, b, e} \quad$ Lisa de las Fuentes ${ }^{c, f} \quad$ Marcos Rothstein $^{d, f}$ \\ Dennis J. Dietzen ${ }^{e}$ Andrew J. Bierhals ${ }^{g}$ Steven C. Cheng ${ }^{d, f}$ Will Ross ${ }^{d, f}$ \\ David Windus ${ }^{d, f}$ Víctor G. Dávila-Román ${ }^{c, f}$ Keith A. Hruskab, d,e,f \\ ${ }^{a}$ Division of Pediatric Nephrology, Southern Illinois University, Springfield, Ill., and ${ }^{b}$ Division of Pediatric \\ Nephrology, 'Cardiovascular Imaging and Clinical Research Core Laboratory, Cardiovascular Division, \\ ${ }^{d}$ Renal Division, ${ }^{e}$ Department of Pediatrics, ${ }^{f}$ Department of Medicine, and ${ }^{9}$ Mallinckrodt Institute of Radiology, \\ Washington University, St. Louis, Mo., USA
}

\section{Key Words}

Cardiovascular disease - Chronic kidney disease .

Phosphate binders · Vascular calcification · Randomized controlled trials

\section{Abstract \\ Background/Aims: Cardiovascular disease (CVD) is in- creased in chronic kidney disease (CKD), and contributed to by the CKD-mineral bone disorder (CKD-MBD). CKD-MBD be- gins in early CKD and its vascular manifestations begin with vascular stiffness proceeding to increased carotid artery in- tima-media thickness (cIMT) and vascular calcification (VC). Phosphorus is associated with this progression and is con- sidered a CVD risk factor in CKD. We hypothesized that mod- ifying phosphorus balance with lanthanum carbonate $\left(\mathrm{LaCO}_{3}\right)$ in early CKD would not produce hypophosphatemia and may affect vascular manifestations of CKD-MBD. Meth- ods: We randomized 38 subjects with normophosphatemic stage $3 \mathrm{CKD}$ to a fixed dose of $\mathrm{LaCO}_{3}$ or matching placebo without adjusting dietary phosphorus in a 12-month ran- domized, double-blind, pilot and feasibility study. The pri- mary outcome was the change in serum phosphorus. Sec-}

ondary outcomes were changes in measures of phosphate homeostasis and vascular stiffness assessed by carotid-femoral pulse wave velocity (PWV), cIMT and VC over 12 months. Results: There were no statistically significant differences between $\mathrm{LaCO}_{3}$ and placebo with respect to the change in serum phosphorus, urinary phosphorus, tubular reabsorption of phosphorus, PWV, CIMT, or VC. Biomarkers of the early CKD-MBD such as plasma fibroblast growth factor-23, Dickkopf-related protein 1 (DKK1), and sclerostin were increased 2- to 3-fold at baseline, but were not affected by $\mathrm{LaCO}_{3}$. Conclusion: Twelve months of $\mathrm{LaCO}_{3}$ had no effect on serum phosphorus and did not alter phosphate homeostasis, PWV, CIMT, VC, or biomarkers of CKD-MBD.

Copyright $\odot 2013$ S. Karger AG, Basel

\section{Introduction}

Chronic kidney disease (CKD) is associated with an increased risk of cardiovascular disease (CVD) compared with the general population $[1,2]$. CVD risk is inversely related to glomerular filtration rate, and begins to rise in early stages of CKD [1-3]. The global burden of CKD-

\section{KARGER}

E-Mail karger@karger.com

www.karger.com/ajn
(C) 2013 S. Karger AG, Basel

0250-8095/13/0382-0158\$38.00/0
Keith A. Hruska, MD

Department of Pediatrics, Washington University

660 S. Euclid Ave., Campus Box 8208

St. Louis, MO 63110 (USA)

E-Mail hruska_k@kids.wustl.edu 
associated CVD is immense, as stage $3 \mathrm{CKD}$ (glomerular filtration: $30-59 \mathrm{ml} / \mathrm{min} / 1.73 \mathrm{~m}^{2}$ ) is prevalent in approximately $10 \%$ of the general population [4]. Furthermore, the mortality rate due to kidney disease-associated CVD eclipses progressive CKD [5], thus highlighting its public health importance. Classic CVD risk factors do not fully explain the increased CVD risk in CKD [5]. Vascular calcification (VC) $[6,7]$ and hyperphosphatemia [8-12] may be important CKD-specific risk factors for CVD, and human and animal studies suggest that hyperphosphatemia stimulates VC [13-17]. Multiple studies have demonstrated an association between serum phosphorus levels and risk factors for CVD, including vascular stiffness [18-21] and VC [19]. In recognition of the roles that disorders of mineral homeostasis and skeletal remodeling play in kidney disease-associated CVD, a syndrome was named in 2006: chronic kidney disease - mineral bone disorder (CKD-MBD) [22].

In early $\mathrm{CKD}$, the serum phosphorus concentration remains normal until late stage 3 or stage 4, but CKD-MBD begins in early CKD [23-25], suggesting that vascular perturbations of CKD occur prior to hyperphosphatemia. Furthermore, studies have demonstrated that the pathogenesis of CKD-MBD and associated VC includes other factors along with changes in phosphate homeostasis. Thus, early intervention in CKD-MBD may affect vascular stiffness before structural abnormalities such as vascular intima-media thickness or calcification are altered.

We hypothesized that in normophosphatemic patients with stage $3 \mathrm{CKD}$, intestinal phosphate binding with lanthanum carbonate $\left(\mathrm{LaCO}_{3}\right)$ would not produce hypophosphatemia but may improve vascular manifestations of the CKD-MBD such as vascular stiffness, carotid artery intima-media thickness (cIMT) and VC. Secondarily, we sought to produce preliminary data that can be used for powering cardiovascular outcomes in future clinical trials of phosphate binders.

\section{Study Population and Methods}

The study protocol was approved by the Human Research Protection Office at Washington University in St. Louis. Subjects were enrolled after giving informed consent in accordance with guidelines from the Declaration of Helsinki. Subjects were eligible if they were older than 18 years of age and had stage $3 \mathrm{CKD}$ (estimated glomerular filtration rate: $30-59 \mathrm{ml} / \mathrm{min} / 1.73 \mathrm{~m}^{2}$ ) using the Modification of Diet in Renal Disease study equation [26]. Exclusion criteria included pregnancy, bone disease, myocardial infarction, congestive heart failure, diastolic dysfunction, or severe hypertension. Each week members of the research team (M.R., S.C.C., W.R., or D.W.) identified their clinic patients that satisfied the inclusion criteria and were interested in the study. Those who provided informed consent to our research nurse allowed a review of their medical records to determine final eligibility before enrollment. The cohort size was predetermined by the available funding. As the subjects were enrolled, they were stratified for age, gender, race, and diabetes status, and then randomized into 2 groups, allocated $1: 1$ to receive either $1,000 \mathrm{mg}$ of $\mathrm{LaCO}_{3}$ or a matching placebo with meals 3 times daily for 12 months. The randomization and doubleblind strategy was designed and maintained by our research pharmacist and statistician. Because practitioners often do not prescribe dietary phosphate restriction in normophosphatemic CKD, dietary phosphate intake was not regulated. All participants were encouraged to track phosphate sources in the diet, but these data were not collected. The purpose of the study was to determine the cohort sizes needed to adequately power primary and secondary outcomes in definitive prospective trials.

\section{Cardiovascular Evaluations}

Cardiovascular assessments were performed at baseline and 12 months. Pulse wave velocity (PWV) was determined by use of applanation tonometry of the carotid and femoral arteries (SphygmoCor; AtCor Medical, Sydney, N.S.W., Australia) as previously described and validated [27-31]. Briefly, subjects were placed in the supine position, and after $10 \mathrm{~min}$ of rest, the heart rate and 3 brachial artery blood pressure measurements were obtained in each arm using a noninvasive manual sphygmomanometer. The high-fidelity transducer was then placed on the subject's right carotid artery and the recorded pressure waveforms were calibrated using an average of the peripheral brachial artery blood pressure. Then the transducer was applied to the right femoral artery and waveforms were again acquired. PWV was determined as the difference in travel time of the pulse wave between the heart and each the right carotid and right femoral arteries, divided by the travel distance of the pulse-wave form. The onset of the Q-wave from the surface electrocardiogram is used to determine the start of the pulse wave. Using a tape measure, the distance between the right carotid artery and suprasternal notch was subtracted from the distance between the right femoral artery and suprasternal notch. The applanation tonometry measurements were performed by a research technician who was blinded to clinical data, echocardiographic results, and treatment group.

cIMT was measured by a single vascular sonographer from Bmode images of both carotid arteries expressed as the average of the far walls of the right and left common carotid arteries; each site represents the average of 3 separate measurements [32]. The intraclass correlation coefficient for repeated measures of the cIMT is 0.91 and for echocardiographic measurements ranges from $0.85-$ 0.90 at our laboratory.

Two-dimensional and M-mode echocardiograms and carotid artery ultrasound were performed by use of commercially available ultrasound equipment (Sequoia-C256, Acuson-Siemens, Mountain View, Calif., USA). Two-dimensional directed echocardiographic measurements included the left ventricular ejection fraction (LVEF) calculated using the biplane method of discs (modified Simpson's method). LV mass was measured by the M-mode-derived cubed method and indexed to height ${ }^{2.7}$ (LVM/ $\mathrm{Ht}^{2.7}$ ) [33]. All measurements were performed in accordance to published guidelines and represent the average of 3 consecutive cardiac cycles obtained by a single observer blinded to all clinical parameters and treatment group [34]. 
Multidetector CT Imaging for Assessment of VC

A 64-slice multidetector CT scanner (Somatom Sensation 64; Siemens Medical Systems, Forchheim, Germany) measured calcium scores and volumes by the Agatston method [35]. After initial scout imaging, the scan fields were set for the neck, chest, and abdomen for the measurement of arterial calcification in the carotids (from the arch to $1 \mathrm{~mm}$ above the carotid bifurcation), coronary arteries, aortic arch, and thoracic aorta (to the top endplate of the T12 vertebral body). The scan parameters included $24 \times 1.2 \mathrm{~mm}$ collimation, 3-mm slice thickness, 0.37 -second rotation time, spiral mode, and $120 \mathrm{kVp}$ at $80 \mathrm{~mA}$ with reconstruction at $60 \%$ of the $\mathrm{R}-\mathrm{R}$ interval. Vascular calcium scores and volumes were measured by use of commercially available software (Vitrea; Vital Images Inc., Minnetonka, Minn., USA) as previously described [35]. All images were evaluated by a single radiologist (A.J.B.) blinded to all clinical characteristics and the treatment group.

\section{Biomarkers of CKD-MBD}

Blood samples were obtained from each subject at the baseline visit and after 12 months of treatment. There was intersubject variation in the time of day that blood samples were obtained. Aliquots of plasma were generated from each sample and used immediately for biochemical testing or frozen at $-80^{\circ} \mathrm{C}$. Plasma levels of fibroblast growth factor-23 (FGF23), Dickkopf-related protein 1 (DKK1) and sclerostin were measured in duplicate using commercially available ELISA kits, according to the manufacturer's instructions (FGF23: Kainos Laboratories, Tokyo, Japan; DKK1: R\&D Systems, Minneapolis, Minn., USA; sclerostin: Teco Medical Group, Sissach, Switzerland).

For safety monitoring, plasma phosphorus, calcium, creatinine, and intact parathyroid hormone (iPTH) levels were measured using standard laboratory methods. A random urine sample was obtained concomitantly to calculate the tubular reabsorption of phosphorus (TRP). A separate 24-hour urine collection was performed at the baseline and 12-month visit to detect a change in creatinine clearance or phosphorus excretion. We used the 24hour creatinine excretion to determine the adequacy of each urine collection. Bone mineral density was assessed using a DXA scan of the lumbar spine at baseline and 12 months.

\section{Outcome Definitions}

The primary outcome was the change in serum phosphorus. Secondary outcomes included change in mean carotid-femoral PWV, a surrogate for vascular stiffness, from baseline to month 12 and changes in serum phosphorus, 24-hour urine phosphorus, TRP, VC, cIMT, LVM/Ht ${ }^{2.7}$, LVEF, and plasma FGF23, DKK1, and sclerostin levels. Given the pilot nature of the design, an empiric number of subjects were enrolled based on available funds.

\section{Statistical Analysis}

Statistical analysis was performed by a statistician who remained blinded to the identity of the subjects and their corresponding study groups. The data were analyzed using the software package SAS 9.1 (Cary, N.C., USA). Calcium volume scores were square-root transformed to limit the likelihood of differences due to variability in multidetector CT scans, as validated and reported previously [36]. A Wilcoxon two-sample test and Student's t test were used to test the differences of continuous variables at baseline and the differences from baseline to the 12-month visit between $\mathrm{LaCO}_{3}$ and placebo. A signed-rank test (nonnormally distributed data) and paired t test (normally distributed data) were used to test differences of continuous variables from baseline to the 12-month visit within the $\mathrm{LaCO}_{3}$ or placebo groups. Normally distributed data are presented as means \pm SD. Nonnormally distributed data are presented as medians (ranges). Categorical variables were compared using a $\chi^{2}$ test. All tests were 2 -tailed; statistical significance was considered at $\mathrm{p}<0.05$.

\section{Results}

\section{Baseline Demographics}

312 subjects that met the inclusion criteria were identified by their primary nephrologist between January 1 and December 31, 2010.58 (19\%) met the study entry criteria (including willingness to participate in the study) and were recruited, 41 were enrolled after a formal review of their medical records to confirm eligibility, and 3 subjects dropped out prior to the first study visit, leaving 38 subjects for the intention-to-treat analysis (fig. 1). Enrollment of a subject required matching for age, sex, race, and diabetes status in a subsequent enrollee, which produced the large gap between screening and enrollment along with consent. The matching is shown in table 1, and gender matching was less successful as there were more males enrolled in the placebo group, but the difference was not statistically significant. Other baseline clinical, cardiovascular, and biochemical characteristics were similar between the groups (tables 1,2). Compliance was assessed at each study visit using pill counts, and was defined as the percentage of prescribed doses that were taken by each subject. The overall mean compliance was $84 \%$ (range: 45-100); compliance was similar in both groups ( $\mathrm{LaCO}_{3}: 85 \%$, placebo: $84 \%$ ).

$\mathrm{LaCO}_{3}$ was well tolerated during the study period. The most commonly reported adverse effect was nausea, which occurred in 5 subjects (26\%) compared to 2 (11\%) in the placebo group. Three subjects with nausea left the study before completing all 5 visits. Headache, constipation, and hyperglycemia each occurred in 1 subject. The subject with hyperglycemia was later diagnosed with type 2 diabetes mellitus. There were no deaths or serious adverse events reported during the study period.

\section{Primary Outcome}

Mean serum phosphorus levels were $3.3-3.5 \mathrm{mg} / \mathrm{dl}$ at baseline in all subjects. There were no instances of hypophosphatemia over the 12 months, and $\mathrm{LaCO}_{3}$ had no significant effect on the primary outcome measure: change in mean fasting serum phosphorus from baseline to month 12 (table 2 ). 
Fig. 1. Enrollment flowchart and random-

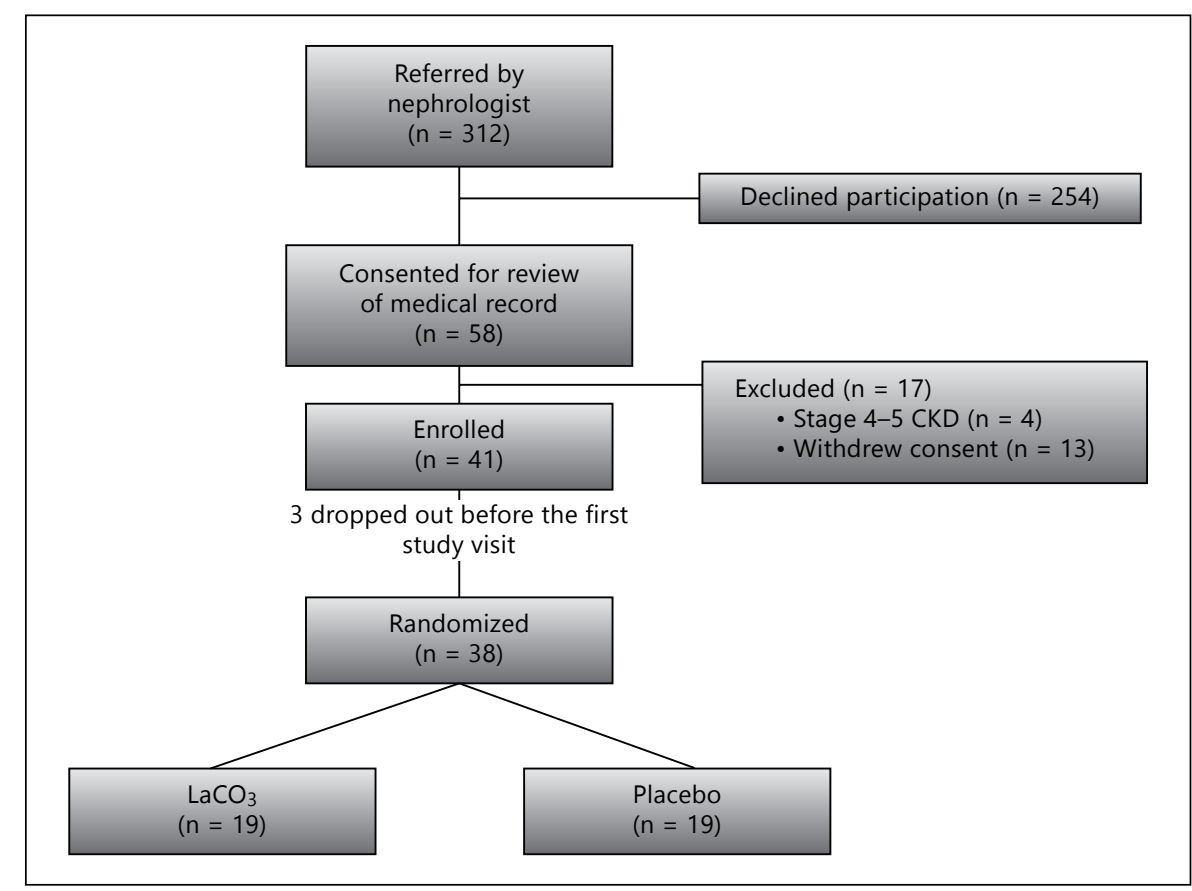

Table 1. Baseline demographic data

\begin{tabular}{lcc}
\hline & $\mathrm{LaCO}_{3}(\mathrm{n}=19)$ & Placebo $(\mathrm{n}=19)$ \\
\hline Demographics & & \\
$\quad$ Age, years & $62 \pm 11$ & $61 \pm 13$ \\
Height, cm & $173 \pm 9$ & $174 \pm 12$ \\
Weight, kg & $97 \pm 20$ & $94 \pm 23$ \\
BMI & $33 \pm 6$ & $31 \pm 5$ \\
Gender, M/F & $9 / 10$ & $14 / 5$ \\
Diabetes mellitus & $7(36)$ & $7(36)$ \\
Race & & \\
African American & $4(21)$ & $5(26)$ \\
Caucasian & $15(79)$ & $12(63)$ \\
Other & $0(0)$ & $2(10)$ \\
\hline
\end{tabular}

All values given as means $\pm \mathrm{SD}$ or $\mathrm{n}(\%)$. There were no significant differences between $\mathrm{LaCO}_{3}$ and placebo.

\section{Secondary Outcomes}

Phosphate Homeostasis and Biomarkers of Early

CKD-MBD

TRP was decreased in both groups at baseline (76 and $77 \%$ in $\mathrm{LaCO}_{3}$ and placebo, respectively) and was not affected by $\mathrm{LaCO}_{3}$ (table 2). Baseline median urinary phosphorus excretion was 707 and $735 \mathrm{mg}$ /day with $\mathrm{LaCO}_{3}$ and placebo, respectively (table 2). Urinary phosphorus excretion decreased to $605 \mathrm{mg} /$ day with $\mathrm{LaCO}_{3}$ and increased to $764 \mathrm{mg}$ /day with placebo by month 12 , but these changes were not significant (table 2, fig. 2a). Baseline mean iPTH levels were 76 and $57 \mathrm{pg} / \mathrm{ml}$ in $\mathrm{LaCO}_{3}$ and placebo, respectively (upper limit of normal in our local assay is $72 \mathrm{pg} / \mathrm{ml}$; table 2). PTH levels did not change significantly over the 12 months in either group (table 2). There were no significant differences in calcium, creatinine, or creatinine clearance between groups at baseline or at month 12 (table 2).

The median FGF23 level in the cohort at baseline was $58 \mathrm{pg} / \mathrm{ml}$ (range: 24-201), which was elevated compared to a reference group of 450 patients in the Diabetes Heart Study with normal glomerular filtration rates that were measured simultaneously with our cohort $[37 \mathrm{pg} / \mathrm{ml}$ (range: $0-539)] . \mathrm{LaCO}_{3}$ did not significantly affect FGF23 levels, which decreased from $69 \mathrm{pg} / \mathrm{ml}$ at baseline to $55 \mathrm{pg} / \mathrm{ml}$ at month 12 in the $\mathrm{LaCO}_{3}$ group, compared to no change from $55 \mathrm{pg} / \mathrm{ml}$ in the placebo group (table 2, fig. 2b).

Baseline levels of DKK1 and sclerostin were 2- to 3 -fold higher in both groups than reference values determined simultaneously in the Diabetes Heart Study cohort that had normal kidney function. After 12 months of treatment there were no differences in plasma DKK1 or sclerostin between or within groups (table 2). Bone mineral density was normal and remained stable or slightly improved in each group after 12 months (table 2). 
Table 2. Comparison of changes in phosphorus, phosphate homeostasis, biomarkers of CVD, and biomarkers of CKD-MBD between groups

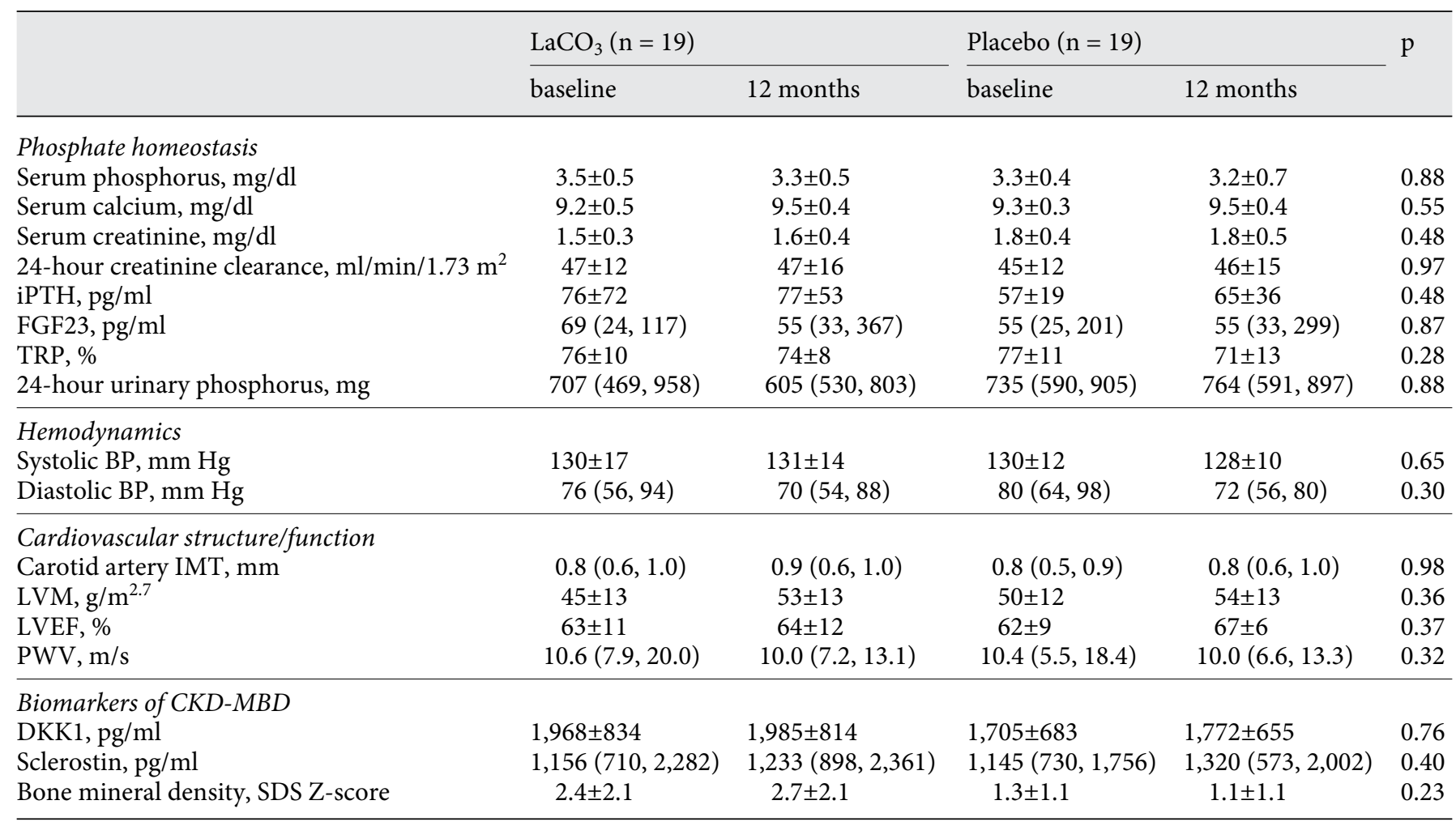

All values given as means \pm SD or medians (ranges). Calcium volume scores have been square-root transformed. Within each group, there were no significant differences from baseline to the 12 -month visit. $\mathrm{p}$ values represent the comparison of the change from baseline to the 12-month visit between the $\mathrm{LaCO}_{3}$ and placebo groups.

\section{Cardiovascular Endpoints}

Blood pressure was well controlled in both groups, with 32 of 38 subjects (84\%) on antihypertensive medications or ACEI for proteinuria throughout the study (table 2). The majority of our cohort demonstrated vascular stiffness at the baseline visit, with PWV greater than the 50th percentile for age using data from the Reference Values for Arterial Stiffness Collaboration (table 2) [37]. The decrease in PWV from baseline to month 12 in the $\mathrm{LaCO}_{3}$ group [10.6 (7.9-20.0) to $10.0(7.2-13.1) \mathrm{m} / \mathrm{s}$; fig. 3], was not significant when compared to placebo (table 2). Baseline cIMT was normal in both groups. With our observed effect on PWV, a statistical power of 0.8 and a probability level of 0.05 , the sample size per group with a 2-tailed hypothesis would need to be 45 patients per group.

There was no change in cIMT from baseline to month 12 within the $\mathrm{LaCO}_{3}$ or placebo groups (table 2). Lowgrade $\mathrm{VC}$ was common in the carotid arteries, coronary arteries, and aorta in both groups at the baseline visit (ta- ble 3) as determined by the Agatston score and calcium volume. After 12 months, the progression of the Agatston score or calcium volume was minimal, and there were no differences in VC in the carotid arteries, coronary arteries, or aorta between the $\mathrm{LaCO}_{3}$ and placebo groups (table 3; online suppl. fig. 1, for all online supplementary material see www.karger.com/doi/10.1159/000353569). LVEF remained stable in both groups. $\mathrm{LVM} / \mathrm{Ht}^{2.7}$ increased within the $\mathrm{LaCO}_{3}$ group after 12 months of treatment, but this trend was not statistically significant (table 2).

\section{Discussion}

This randomized, placebo-controlled, pilot and feasibility study demonstrated that 12 months of treatment with the phosphate binder $\mathrm{LaCO}_{3}$ had no significant effect on the serum phosphorus level in normophospha- 


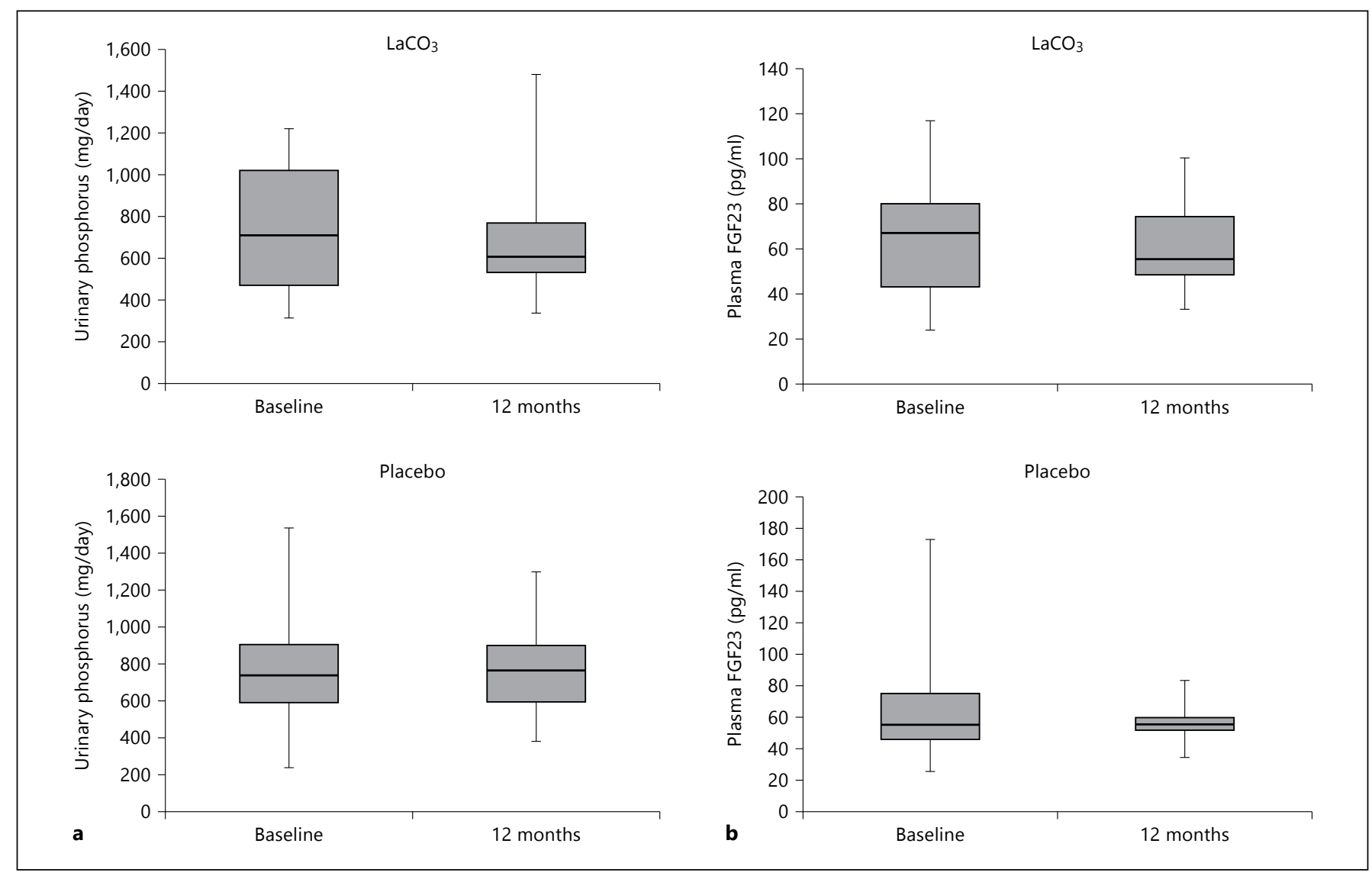

Fig. 2. Urinary phosphorus and FGF23 levels in the $\mathrm{LaCO}_{3}$ and placebo groups at baseline and at 12 months. Boxplot representation of urinary phosphorus (a) and FGF23 (b) levels at baseline and
12 months. Median values are the horizontal lines within the shaded areas. The shaded areas represent the 75th (top) to 25th (bottom) percentiles, and the vertical lines with whiskers represent the full range. temic patients with CKD stage $3 \mathrm{a}$ [38]. These results were compatible with our preclinical studies of phosphate binders in models of normophosphatemic early CKD. $\mathrm{LaCO}_{3}$ had no significant effect on urine phosphorus excretion, TRP, or plasma levels of the phosphaturic hormone FGF23. Furthermore, $\mathrm{LaCO}_{3}$ did not alter PWV, cIMT, or VC compared to placebo.

Other investigators have demonstrated small or no changes in phosphate homeostasis during intervention with phosphate binders in early CKD $[39,40]$. Hill et al. [40] showed that the phosphate binder calcium carbonate produced little change in phosphate homeostasis in normophosphatemic subjects, in agreement with our results using the binder $\mathrm{LaCO}_{3}$. Our cohort size was twice that of Gonzalez-Parra et al. [39], who performed an open-label study of $\mathrm{LaCO}_{3}$ in hyperphosphatemic patients. They also reported a lack of change in serum phosphorus, but also significant reductions in urinary phos-

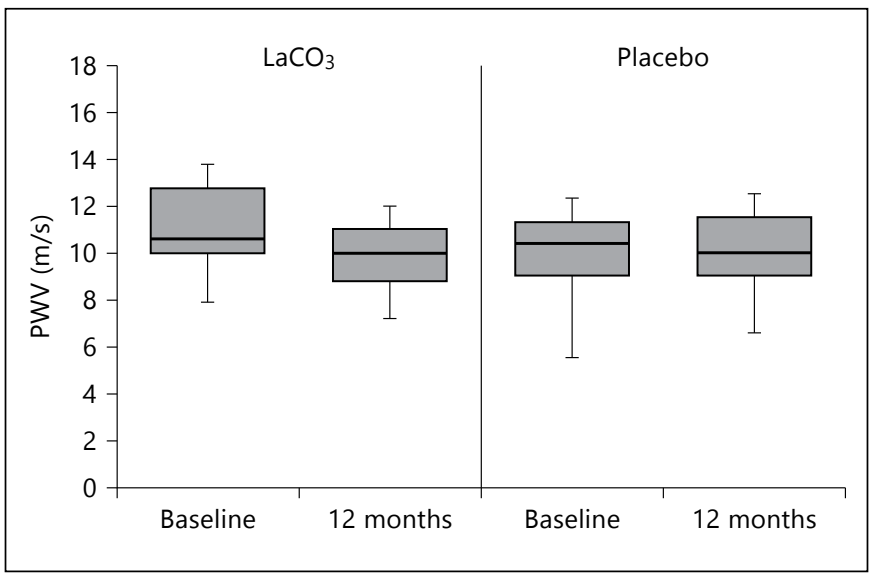

Fig. 3. Effect of $\mathrm{LaCO}_{3}$ on PWV. Boxplot representation of carotidfemoral PWV data at baseline and the 12-month visit in each group. The line in the shaded area is the median value, the top of the shaded area is the 75th percentile, the bottom of the shaded area is the 25 th percentile and the whiskers represent the range of the values. 
Table 3. VC between groups

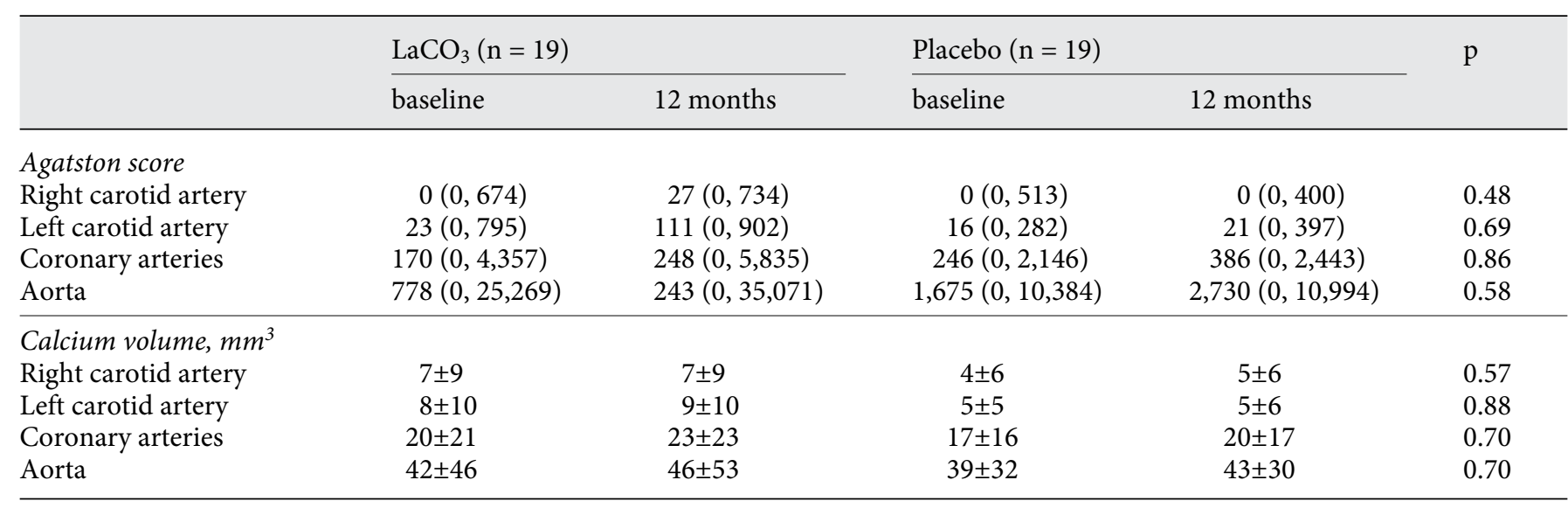

All values given as means \pm SD or medians (range). Calcium volume scores have been square-root transformed. Within each group, there were no significant differences from baseline to the 12-month visit. $\mathrm{p}$ values represent the comparison of the change from baseline to the 12-month visit between the $\mathrm{LaCO}_{3}$ and placebo groups.

phate excretion and increased TRP that were not detected in our cohort. Our study was designed as a pilot and feasibility study, and there was insufficient power to detect changes in phosphate homeostasis during the study. Using a 2-tailed $\alpha$ of 0.05 , a post hoc analysis revealed that our sample size of 38 subjects was adequately powered to detect a $0.5-\mathrm{mg} / \mathrm{dl}$ difference in serum phosphorus levels, a 10-percentage point difference in TRP, and 400-mg difference in 24-hour urine phosphorus between groups with $80 \%$ power. Alternatively, passive phosphate absorption may be resistant to binders in the presence of normophosphatemia, and therefore the change in phosphate homeostasis in our study was truly insignificant. Several studies of phosphate binders in early CKD have shown a lack of change in FGF23 levels but modest changes in phosphate homeostasis [41-43]. These studies were in cohorts containing hyperphosphatemic subjects with more advanced kidney disease than our cohort, which may account for the lack of change in FGF23 levels or phosphate homeostasis that we observed. In contrast, other reports have shown reductions in FGF23 with phosphate binders $[39,44,45]$. Closer inspection of these studies reveals higher baseline levels of FGF23 than in our cohort, shorter periods of treatment, and changes in levels similar to those reported here (table 2). Although it is not routine clinical practice, coupling dietary restriction with phosphate binders has recently been shown to decrease FGF23 levels in CKD [46, 47]. Sigrist et al. [46] suggest that dietary restriction alone may be adequate for reducing FGF23 levels in early $\mathrm{CKD}$, but they demon- strate additivity with aluminum-based phosphate binders. Thus, it is possible that phosphate binders plus dietary phosphorus restriction may be necessary to reduce FGF23 levels in early CKD.

PTH levels were normal at baseline in our cohort as a whole $(68 \mathrm{pg} / \mathrm{ml})$, and were unchanged by $\mathrm{LaCO}_{3}$ just as in the $\mathrm{LaCO}_{3}$ arm in Block et al. [41]. Thus, the changes in phosphate homeostasis in our study were minimal, but consistent across all parameters used to assess phosphate homeostasis.

Recent data demonstrate that CKD-MBD begins in early CKD. Elevations of FGF23 in the skeleton and the circulation are present in CKD stages 2-3 [24, 48, 49], along with reductions in the TRP [49] and the onset of vascular stiffness [18]. Our results are in agreement with these studies, showing that in normophosphatemic subjects with stage $3 \mathrm{CKD}$, circulating FGF23, DKK1, and sclerostin were increased and TRP was decreased at baseline. All subjects had elevated PWV at baseline, confirming that vascular stiffness was present.

An important contribution of our study is the assessment of vascular stiffness in each treatment arm using carotid-femoral PWV. After 12 months of therapy, $\mathrm{LaCO}_{3}$ did not significantly improve PWV compared to placebo. Recent clinical and translational studies have highlighted the importance of FGF23 signaling in vascular stiffness and overall CVD risk $[50,51]$. We therefore speculate that the lack of significant improvement in vascular stiffness in our study may be linked to the lack of significant changes in phosphate homeostasis and FGF23 levels. Fu- 
ture studies that combine phosphate binders with dietary phosphorus restriction may produce the necessary changes in phosphate homeostasis and FGF23 to reduce markers of CVD risk such as PWV. For our observed effects on $\mathrm{PWV}$, a statistical power of 0.8 , and a probability level of 0.05 , the sample size per group with a 2 -tailed hypothesis would need to be 45 patients per group.

Our cohort demonstrated normal ranges of cIMT, but significant VC at baseline with no significant change in either parameter after 12 months of $\mathrm{LaCO}_{3}$. The normal cIMT range in our cohort may reflect the early stage of $\mathrm{CKD}$ and could explain the observed lack of improvement with $\mathrm{LaCO}_{3}$. Although $\mathrm{VC}$ was detectable in the cohort at baseline, the progression over 12 months was minimal in both the $\mathrm{LaCO}_{3}$ and placebo groups. Our results do not disagree with the recent studies from Block et al. [41] that reported increased coronary artery calcification in a composite cohort of subjects with CKD stages 3-4 receiving calcium acetate, $\mathrm{LaCO}_{3}$, or sevelamer carbonate. In their study, the progression of $\mathrm{VC}$ in the $\mathrm{LaCO}_{3}$ arm also did not differ from placebo. The progression of VC in the combined study population appeared to derive from the subgroup treated with calcium acetate. Despite the initial consensus around phosphorus as a CVD risk factor [8-12, 52], recent studies have questioned this concept and therefore the impetus to intervene in phosphate homeostasis early in the course of CKD $[41,53]$.

There are several limitations to this study. The first is that the study was underpowered for the cardiovascular outcomes, especially for detection of the modest differences we observed for each outcome between groups. Secondly, the period of observation may have been too short to observe progression in the surrogates of CVD selected for study. This will influence the design of future studies seeking to intervene in the cardiovascular morbidity associated with CKD.

We conclude that $\mathrm{LaCO}_{3}$ therapy is feasible without hypophosphatemia in CKD stage 3a. In this prospective pilot and feasibility study in early CKD, 12 months of $\mathrm{LaCO}_{3}$ was associated with no significant changes in phosphate homeostasis and no improvement in PWV (a measure of vascular stiffness), cIMT, or VC. This study does not lend support for further study of phosphate binders in early-stage CKD because of the failure to affect phosphate homeostasis. A practical design that incorporates effective change in phosphate homeostasis is worthy of additional study.

\section{Acknowledgments}

The authors are grateful to Julie Nobbe, Pharm.D., who maintained the randomization and double-blind strategy. We thank Jingnan Mao for her assistance as a statistician, and Daniel Coyne for reviewing the results and adverse events in lieu of a data and safety monitoring committee. The $\mathrm{LaCO}_{3}$ and matched placebo were provided by Shire U.S. Pharmaceuticals Inc. The study was funded by Shire U.S. Pharmaceuticals Inc., and by NIH grants DK 070790, DK 089137 (K.A.H.), KL2RR024994, and UL1 RR024992 (Washington University).

\section{Disclosure Statement}

K.A.H. has been a consultant for or the recipient of research funding from Shire, Genzyme and Fresenius. This work was funded in part by Shire U.S. Pharmaceuticals Inc., and by NIH grants DK 070790 and DK 089137 (K.A.H.), KL2RR024994 (M.E.S.), and UL1 RR024992 (Washington University).

\section{References}

$>1$ Go AS, Chertow GM, Fan D, McCulloch CE, Hsu Cy: Chronic kidney disease and the risks of death, cardiovascular events, and hospitalization. New Engl J Med 2004;351:1296-1305.

$\checkmark 2$ Culleton BF, Larson MG, Wilson PWF, Evans JC, Parfrey PS, Levy D: Cardiovascular disease and mortality in a community based cohort with mild renal insufficiency. Kidney Int 1999;56:2214-2219.

-3 Foley RN, Parfrey PS, Sarnak MJ: Clinical epidemiology of cardiovascular disease in chronic renal disease. Am J Kidney Dis 1998; 32:S112-S119.

4 Coresh J, Selvin E, Stevens LA, Manzi J, Kusek JW, Eggers P, Van Lente F, Levey AS: Prevalence of chronic kidney disease in the United States. JAMA 2007;298:2038-2047.
5 Foley RN, Murray AM, Li S, Herzog CA, McBean AM, Eggers PW, Collins AJ: Chronic kidney disease and the risk for cardiovascular disease, renal replacement, and death in the United States Medicare population, 1998 to 1999. J Am Soc Nephrol 2005;16:489-495.

-6 Blacher J, Guerin AP, Pannier B, Marchais SJ, London GM: Arterial calcifications, arterial stiffness, and cardiovascular risk in endstage renal disease. Hypertension 2001;38:938942.

7 London GM, Guerin AP, Marchais SJ, Metivier F, Pannier B, Adda H: Arterial media calcification in endstage renal diseases: impact on all cause and cardiovascular mortality. Nephrol Dial Transplant 2003;18:17311740 .
8 Block GA, Hulbert Shearon TE, Levin NW, Port FK: Association of serum phosphorus and calcium $\mathrm{x}$ phosphate product with mortality risk in chronic hemodialysis patients: a national study. Am J Kidney Dis 1998;31: 607-617.

$\checkmark 9$ Kestenbaum B, Sampson JN, Rudser KD, Patterson DJ, Seliger SL, Young B, Sherrard DJ, Andress DL: Serum phosphate levels and mortality risk among people with chronic kidney disease. J Am Soc Nephrol 2005;16: 520-528.

10 Tonelli M, Sacks F, Pfeffer M, Gao Z, Curhan G, Cholesterol and Recurrent Events Trial I: Relation between serum phosphate level and cardiovascular event rate in people with coronary disease. Circulation 2005;112:2627-2633. 
11 Dhingra R, Sullivan LM, Fox CS, Wang TJ, D’Agostino RB Sr, Gaziano JM, Vasan RS: Relations of serum phosphorus and calcium levels to the incidence of cardiovascular disease in the community. Arch Intern Med 2007; 167:879-885.

$\checkmark 12$ Palmer SC, Hayen A, Macaskill P, Pellegrini F, Craig JC, Elder GJ, Strippoli GF: Serum levels of phosphorus, parathyroid hormone, and calcium and risks of death and cardiovascular disease in individuals with chronic kidney disease. JAMA 2011;305:1119-1127.

$\checkmark 13$ El-Abbadi MM, Pai AS, Leaf EM, Yang HY, Bartley BA, Quan KK, Ingalls CM, Liao HW, Giachelli CM: Phosphate feeding induces arterial medial calcification in uremic mice: role of serum phosphorus, fibroblast growth factor-23, and osteopontin. Kidney Int 2009; 75: 1297-1307.

14 Shanahan CM, Crouthamel MH, Kapustin A, Giachelli CM: Arterial calcification in chronic kidney disease: key roles for calcium and phosphate. Circ Res 2011;109:697-711.

$\checkmark 15$ Moe SM, Chen NX: Mechanisms of vascular calcification in chronic kidney disease. J Am Soc Nephrol 2008;19:213-216.

-16 Davies MR, Hruska KA: Pathophysiological mechanisms of vascular calcification in endstage renal disease. Kidney Int 2001;60:472479.

-17 Mathew S, Lund R, Strebeck F, Tustison KS, Geurs T, Hruska KA: Reversal of the adynamic bone disorder and decreased vascular calcification in chronic kidney disease by sevelamer carbonate therapy. J Am Soc Nephrol 2007; 18:122-130.

-18 Ix JH, de Boer IH, Peralta CA, Adeney KL, Duprez DA, Jenny NS, Siscovick DS, Kestenbaum BR: Serum phosphorus concentrations and arterial stiffness among individuals with normal kidney function to moderate kidney disease in MESA. Clin J Am Soc Nephrol 2009;4:609-615.

$\checkmark 19$ Adeney KL, Siscovick DS, Ix JH, Seliger SL, Shlipak MG, Jenny NS, Kestenbaum BR: Association of serum phosphate with vascular and valvular calcification in moderate CKD. J Am Soc Nephrol 2009;20:381-387.

20 Meng J, Wassel CL, Kestenbaum BR, Collins TC, Criqul MH, Lewis CE, Cummings SR, Ix $\mathrm{JH}$ : Serum phosphorus levels and the spectrum of ankle brachial index in older men. The Osteoporotic Fractures in Men (MrOS) study. Am J Epidemiol 2010;171:909-916.

-21 Blacher J, Guerin AP, Pannier B, Marchais SJ, Safar ME, London GM: Impact of aortic stiffness on survival in end-stage renal disease. Circulation 1999;99:2434-2439.

22 Moe S, Drueke T, Cunningham J, Goodman W, Martin K, Olgaard K, Ott S, Sprague S, Lameire N, Eknoyan G: Definition, evaluation, and classification of renal osteodystrophy: a position statement from Kidney Disease: Improving Global Outcomes (KDIGO). Kidney Int 2006;69:1945-1953.

-23 Fang Y, Ginsberg C, Sugatani T, Faugere MC, Malluche H, Hruska KA: The early chronic kidney disease-mineral bone disorder (CKDMBD) stimulates vascular calcification. Kidney Int 2013, in press.

24 Pereira RC, Juppner H, Azucena-Serrano CE, Yadin O, Salusky IB, Wesseling-Perry K: Patterns of FGF-23, DMP1 and MEPE expression in patients with chronic kidney disease. Bone 2009;45:1161-1168.

25 Sabbagh Y, Graciolli FG, O’Brien S, Tang W, dos Reis LM, Ryan S, Phillips L, Boulanger J, Song W, Bracken C, Liu S, Ledbetter S, Dechow P, Canziani ME, Carvalho AB, Jorgetti V, Moyses RM, Schiavi SC: Repression of osteocyte $\mathrm{Wnt} / \beta$-catenin signaling is an early event in the progression of renal osteodystrophy. J Bone Miner Res 2012;27:1757-1772.

26 Levey AS, Bosch JP, Lewis JB, Greene T, Rogers N, Roth D: A more accurate method to estimate glomerular filtration rate from serum creatinine: a new prediction equation. Modification of Diet in Renal Disease Study Group. Ann Intern Med 1999;130:461-470.

27 Pauca AL, O’Rourke MF, Kon ND: Prospective evaluation of a method for estimating ascending aortic pressure from the radial artery pressure waveform. Hypertension 2001;38: 932-937.

28 Van Bortel LM, Balkestein EJ, van der Heijden-Spek JJ, Vanmolkot FH, Staessen JA, Kragten JA, Vredeveld JW, Safar ME, Boudier HAS, Hoeks AP: Noninvasive assessment of local arterial pulse pressure: comparison of applanation tonometry and echo-tracking. J Hypertens 2001;19:1037-1044.

29 O’Rourke MF, Adji A: An updated clinical primer on large artery mechanics: implications of pulse waveform analysis and arterial tonometry. Curr Opin Cardiol 2005;20:275281.

30 O'Rourke MF, Pauca A, Jiang XJ: Pulse wave analysis. Br J Clin Pharmacol 2001;51:507522.

-31 Wilkinson IB, Fuchs SA, Jansen IM, Spratt JC, Murray GD, Cockcroft JR, Webb DJ: Reproducibility of pulse wave velocity and augmentation index measured by pulse wave analysis. J Hypertens 1998;16:2079-2084.

- 32 Stein JH, Korcarz CE, Hurst RT, Lonn E, Kendall CB, Mohler ER, Najjar SS, Rembold CM, Post WS: Use of carotid ultrasound to identify subclinical vascular disease and evaluate cardiovascular disease risk: a consensus statement from the American Society of Echocardiography Carotid Intima-Media Thickness Task Force. Endorsed by the Society for Vascular Medicine. J Am Soc Echocardiogr 2008; 21:93-111.

-33 de Simone G, Daniels SR, Devereux RB, Meyer RA, Roman MJ, de Divitiis O, Alderman MH: Left ventricular mass and body size in normotensive children and adults: assessment of allometric relations and impact of overweight. J Am Coll Cardiol 1992;20:12511260.

-34 Nagueh SF, Appleton CP, Gillebert TC, Marino $\mathrm{PN}, \mathrm{Oh} \mathrm{JK}$, Smiseth $\mathrm{OA}$, Waggoner $\mathrm{AD}$, Flachskampf FA, Pellikka PA, Evangelisa A:
Recommendations for the evaluation of left ventricular diastolic function by echocardiography. Eur J Echocardiography 2009;10:165193.

35 Agatston AS, Janowitz WR, Hildner FJ, Zusmer NR, Viamonte M Jr, Detrano R: Quantification of coronary artery calcium using ultrafast computed tomography. J Am Coll Cardiol 1990;15:827-832.

36 Mathews SJ, de las Fuentes L, Podaralla P, Cabellon A, Zheng S, Bierhals A, Spence K, Slatopolsky E, Davila-Roman VG, Delmez JA: Effects of sodium thiosulfate on vascular calcification in end-stage renal disease: a pilot study of feasibility, safety and efficacy. Am J Nephrol 2011;33:131-138.

-37 Reference Values for Arterial Stiffness Collaboration: Determinants of pulse wave velocity in healthy people and in the presence of cardiovascular risk factors: 'establishing normal and reference values'. Eur Heart J 2010; 31:2338-2350.

38 KDIGO 2013 clinical practice guideline for the evaluation and management of chronic kidney disease. Kidney Int Suppl 2013;3:1150 .

-39 Gonzalez-Parra E, Gonzalez-Casaus ML, Galán $\mathrm{A}$, Martinez-Calero $\mathrm{A}$, Navas $\mathrm{V}$, Rodriguez $\mathrm{M}$, Ortiz A: Lanthanum carbonate reduces FGF23 in chronic kidney disease stage 3 patients. Nephrol Dial Transplant 2011;26: 2567-2571.

40 Hill KM, Martin BR, Wastney ME, McCabe GP, Moe SM, Weaver CM, Peacock M: Oral calcium carbonate affects calcium but not phosphorus balance in stage 34 chronic kidney disease. Kidney Int 2013;83:959-966.

41 Block GA, Wheeler DC, Persky MS, Kestenbaum B, Ketteler M, Spiegel DM, Allison MA, Asplin J, Smits G, Hoofnagle AN, Kooienga L, Thadhani R, Mannstadt M, Wolf M, Chertow GM: Effects of phosphate binders in moderate CKD. J Am Soc Nephrol 2012;23: 1407-1415.

42 Isakova T, Gutierrez OM, Smith K, Epstein M, Keating LK, Juppner H, Wolf M: Pilot study of dietary phosphorus restriction and phosphorus binders to target fibroblast growth factor 23 in patients with chronic kidney disease. Nephrol Dial Transplant 2011;26: 584-591.

43 Block GA, Persky MS, Ketteler M, Kestenbaum B, Thadhani R, Kooienga L, Spiegel D, Asplin J, Ehrlich J, Dennis V, Nissenson A, Chertow GM, Wheeler DC: A randomized double-blind pilot study of serum phosphorus normalization in chronic kidney disease: a new paradigm for clinical outcomes studies in nephrology. Hemodialysis Int 2009;13: 360-362.

44 Yilmaz MI, Sonmez A, Saglam M, Yaman H, Kilic S, Eyileten T, Caglar K, Oguz Y, Vural A, Yenicesu M, Mallamaci F, Zoccali C: Comparison of calcium acetate and sevelamer on vascular function and fibroblast growth factor 23 in CKD patients: a randomized clinical trial. Am J Kidney Dis 2012;59:177-185. 
45 Oliveira RB, Cancela AL, Graciolli FG, Dos Reis LM, Draibe SA, Cuppari L, Carvalho AB, Jorgetti V, Canziani ME, Moysés RM: Early control of PTH and FGF23 in normophosphatemic CKD patients: a new target in CKDMBD therapy? Clin J Am Soc Nephrol 2010. 5:286-291.

46 Sigrist M, Tang M, Beaulieu M, Espino-Hernandez G, Er L, Djurdjev O, Levin A: Responsiveness of FGF-23 and mineral metabolism to altered dietary phosphate intake in chronic kidney disease (CKD): results of a randomized trial. Nephrol Dial Transplant 2013;28: 161-169.

47 Isakova T, Barchi-Chung A, Enfield G, Smith K, Vargas G, Houston J, Xie H, Wahl P, Schiavenato E, Dosch A, Gutierrez OM, Diego J, Lenz O, Contreras G, Mendez A, Weiner R, Wolf M: Effects of dietary phosphate restriction and lanthanum carbonate on FGF23 in CKD. J Am Soc Nephrol 2012;23:P45A.
$48 \mathrm{Ix} \mathrm{JH}$, Shlipak MG, Wassel CL, Whooley MA: Fibroblast growth factor-23 and early decrements in kidney function: the Heart and Soul Study. Nephrol Dial Transplant 2010;25:993997.

49 Isakova T, Wahl P, Vargas GS, Gutierrez OM, Scialla J, Xie H, Appleby D, Nessel L, Bellovich K, Chen J, Hamm L, Gadegbeku C, Horwitz E, Townsend RR, Anderson CA, Lash JP, Hsu $\mathrm{Cy}$, Leonard MB, Wolf M: Fibroblast growth factor 23 is elevated before parathyroid hormone and phosphate in chronic kidney disease. Kidney Int 2011;79:1370-1378.

50 Faul C, Amaral AP, Oskouei B, Hu MC, Sloan A, Isakova T, Gutierrez OM, AquillonPrada R, Lincoln J, Hare JM, Mundel P, Morales A, Scialla J, Fischer M, Soliman EZ, Chen J, Go AS, Rosas SE, Nessel L, Townsend RR, Feldman HI, John Sutton M, Ojo A, Gadegbeku C, Di Marco GS, Reuter S, Kentrup D, Tiemann K, Brand M, Hill JA, Moe OW, Kuro-O M, Kusek JW, Keane MG, Wolf M: FGF23 induces left ventricular hypertrophy. J Clin Invest 2011;121:4393-4408.
51 Wolf M, Molnar MZ, Amaral AP, Czira ME, Rudas A, Ujszaszi A, Kiss I, Rosivall L, Kosa J, Lakatos P, Kovesdy CP, Mucsi I: Elevated fibroblast growth factor 23 is a risk factor for kidney transplant loss and mortality. J Am Soc Nephrol 2011;22:956966.

52 Foley RN, Collins AJ, Herzog CA, Ishani A, Kalra PA: Serum phosphorus levels associate with coronary atherosclerosis in young adults. J Am Soc Nephrol 2009;20:397-404.

53 Grandi NC, Brenner H, Hahmann H, Wüsten B, März W, Rothenbacher D, Breitling LP: Calcium, phosphate and the risk of cardiovascular events and all-cause mortality in a population with stable coronary heart disease. Heart 2012;98:926-933. 